\title{
RECENSÃO DO LIVRO AZARES Y DECISIONES: RECUERDOS PERSONALES DE HORACIO CAPEL
}

\author{
Francisco Magalhães
}

Universidade de Lisboa - Instituto de Geografia e Ordenamento do Território

\section{Resumo}

Em 2019, o geógrafo Horacio Capel publicou um livro de cariz autobiográfico. A presente recensão analisa o conteúdo da mais recente obra do autor, fazendo referência aos aspetos mais relevantes para a ciência geográfica.

oracio Capel Sáez, Professor Catedrático Emérito da Universidade de Barcelona, é o geógrafo mais "renovador e influente de Espanha" (Gonzalez, 2013, p. 1) e uma das "figuras mais proeminentes da Geografia europeia" (Romão, 2017, p. 2). Nascido, como geógrafo, num contexto em que o paradigma da geografia regional vidaliana dominava as investigações geográficas, Capel processou, a partir dos anos 60 do século $X X$, a revolução neopositivista na Geografia espanhola, tendo-Ihe cabido em particular desempenhar um papel destacado nos primeiros trabalhos de geografia urbana realizados no contexto universitário espanhol (Benach \& Casals, 2015, p. 76). Esta fase da sua carreira científica, em que se dedicou aos estudos urbanos tendo por base as metodologias teórico-quantitativas, culminou na sua tese de doutoramento, intitulada La red urbana española, 1950-1960 (1972). A partir da década de 1970 dedica esforços significativos ao estudo da história, teoria e epistemologia da Geografia, esforços que, entre muitas outras publicações, resultaram numa das suas obras de referência: Filosofia y Ciencia en la Geografía Contemporanea (1988). Em meados da década de 1990 retomou os estudos urbanos, sendo pioneiro na utilização das TIC no âmbito da Geografia (Gonzalez, 2013, p. 7).

Horacio Capel acaba de publicar na editora Doce Calles o seu livro de memórias, significativamente intitulado Azares y Decisiones: recurdos personales, que aqui recenseamos. Este livro resulta da convicção do autor de que o género autobiográfico "pode ajudar a reconstruir a história de um tempo, dos lugares, das profissões, de uma sociedade", neste caso da Geografia. Com o relato da sua vida pessoal, mas sobretudo da sua vida enquanto geógrafo, Horacio Capel traz-nos a história da evolução das perspetivas e epistemologia da Geografia na academia 
espanhola. A obra que agora se apresenta, surge, assim, como um documento precioso para a compreensão da história da Geografia espanhola, mas também mundial. Azares y Decisiones, organiza-se em 9 capítulos, sendo que estes obedecem genericamente a uma ordem cronológica. Nos dois últimos capítulos, Capel faz uma apreciação da sua própria obra e das razões intelectuais e sociais que o levaram a trabalhar sobre os problemas que escolheu.

O primeiro capítulo é dedicado à sua infância e juventude em Lorca. Embora tenha nascido em Málaga, o essencial da infância de Horacio Capel aconteceu em Lorca, "pelo que [se sente] mais murciano que andaluz" (p. 17). A sociedade espanhola, nas décadas de 40 e 50 do século $\mathrm{XX}$, vivia as consequências do pós-guerra e do franquismo, existindo graves carências e desigualdades. É neste contexto que o autor cresce em Lorca, cidade do sudeste espanhol, marcada pela aridez geral e por uma forte emigração. Durante o mês de agosto ia com a família até Albanchez, localidade na serra dos Filabres marcada pela migração interna e pelas relações cidade-campo. Entre rituais religiosos e celebrações impostas pelo regime franquista, Horacio Capel fez a sua formação pré-escolar e primária no Colégio de San Francisco e a instrução secundária no Instituto José Ibáñez Martín. O ensino secundário marca a sua adolescência pela qualidade dos colegas e professores, dos quais conserva boas memórias e que, como nos lembra, foram decisivos para a sua formação intelectual. No final desta etapa, tomou a decisão de ir para a Universidade de Murcia fazer a licenciatura em Filosofia e Letras.

O segundo capítulo aborda a vida em Múrcia, onde o jovem estudante chega em setembro de 1959. Sendo que Francisco Franco só viria a morrer em 1975, por estes anos vivia-se, em Espanha, num regime ditatorial, que se fazia sentir em muitos aspetos da vida social e privada, dos quais a realidade académica não era exceção. Uma boa ilustração disso é a obra Escuela de Mandarinos, de Miguel Espinosa, que o autor toma por referência para a ilustração deste contexto. Na Universidade de Murcia, Capel conheceu Juan Vilá Valentí, geógrafo que considera como seu mestre. Em 1964 termina a sua dissertação de licenciatura, La población y los movimentos migratorios en el municipio de Lorca (Murcia). Imediatamente após a apresentação deste estudo, ainda durante o mês de setembro foi nomeado Professor Ajudante na Faculdade de Letras da Universidade de Murcia. Refira-se ainda que, enquanto frequenta a Universidade de Murcia, Horacio Capel vive no Colegio Mayor Cardenal Belluga, o que foi marcante tanto a título pessoal, tendo forjado aí diversas amizades que Ihe ficariam para os anos seguintes, como do ponto de vista intelectual.

$\mathrm{Na}$ terceira parte deste livro Capel fala-nos sobre os primeiros tempos na Universidade de Barcelona. Em 1965, Vilá Valentí tinha abandonado a Universidade de Murcia, transferindo-se para Barcelona. No ano seguinte, por ocasião da criação do Departamento de Geografia da Universidade de Barcelona, Horacio Capel foi convidado para aí dar aulas como Professor Adjunto. Rapidamente se apaixonou por Barcelona e pela Catalunha. Em 1967, como consequência da criação do mesmo Departamento de Geografia, surge Revista de Geografía, a qual vem dar particular visibilidade à Geografia de Barcelona. Com a incumbência de lecionar a unidade curricular Geografia Urbana, Horacio Capel criou a Equipo Urbana, a qual serviu para dar uma denominação coletiva aos trabalhos que desenvolvia com os estudantes. A sua tese de doutoramento, La red urbana española, 1950-1960, é apresentada na Universidade de Barcelona em 1972. 
Depois de uma década sem qualquer reunião geral dos geógrafos espanhóis, em 1975 acontece em Oviedo um Congresso de Geografía. Este encontro foi particularmente importante para o autor dado que nele ficaram bem evidentes as diferenças de paradigma entre "los mayores", isto é, os geógrafos regionalistas, como diz, e "los jóvenes", que praticavam e defendiam novas ideias geográficas (p. 108). Tendo este pano de fundo, Horacio Capel publica em 1976 "La Geografía española tras la guerra civil", iniciando com este trabalho a série Geo Crítica: Cuadernos Críticos de Geografia Humana. Paralelamente às publicações da Geo Crítica, Capel desenvolve também uma coleção de livros de temáticas relacionadas com a Geografia na Editorial Libros de la Frontera, de Barcelona. Por esta altura faziam-se sentir também os efeitos da transição do franquismo para a democracia.

“¿Sirven de algo los contactos, los viajes y los congresos?” é o título do quarto capítulo deste livro. Está centrado na análise da importância que as viagens e os congressos têm na vida de um académico. Foi através dessas viagens e reuniões científicas que Horacio Capel conheceu diferentes individualidades da Geografia e de outras áreas do conhecimento, proporcionando-se uma troca de saberes muito proveitosa. Neste capítulo o autor faz também referência ao início das suas relações com os países latino-americanos.

O quinto capítulo de Azares y Decisiones é dedicado à atividade científica que o autor desenvolveu na última década do milénio passado. Paralelamente à prática docente, onde era possível interagir com os mais variados perfis de alunos, desenvolveu as suas investigações, assegurando sempre as duas componentes de atividade que cabem a um professor universitário. No caso de Capel, da combinação destas duas vertentes do seu labor resultou, desde logo, a orientação de mais de 70 teses de doutoramento, que são, segundo o autor, uma das mais importantes atividades que se realizam nas universidades. A partir de 1994 a revista Geo Crítica que atingira o seu número 100 - passa a ser publicada em formato eletrónico. Assim, surge o portal Geocrítica, que, rapidamente, viria a incorporar novas revistas, sendo atualmente constituído pela Scripta Nova, Scripta Vetera e Biblio 3W. A partir de 1999 surgem os Coloquios Internacionales de Geocrítica, de realização bianual, nos quais têm participado inúmeros investigadores, em particular vinculados a universidades do espaço latino-americano.

A sexta parte do livro concentra-se na atividade científica que o autor desenvolve entre a última década do século XX e o ano de 2015. Horacio Capel faz uma descrição exaustiva das viagens e congressos em que participou ao longo deste período, destacando a relação que manteve com os países ibero-americanos. Essa participação em congressos fez com que voltasse muitas vezes a dedicar esforços aos temas relativos à história das ciências, embora por estes anos tivesse também retomado os estudos urbanos, como referimos. Em 2008, Capel recebe 0 Prix Vautrin Lud - considerado o Nobel da Geografia -, sendo o primeiro geógrafo espanhol a receber este galardão, correspondente ao reconhecimento internacional da importância das investigações desenvolvidas ao longo da sua carreira.

O sétimo capítulo é mais intimista, onde Capel aborda as questões mais pessoais e familiares. Fala-nos da sua mulher, a geógrafa Mercedes Tatjer, das suas três filhas, dos netos, das amizades que foi criando ao longo da vida e dos seus hábitos diários. Além de falar da família e amigos, Horacio Capel expõe-nos as preocupações que tem quanto ao futuro dos milhares de livros que foi acumulando na sua biblioteca pessoal. Fala-nos também da situação política da 
Catalunha, afirmando que é imperativo restabelecer as pontes de diálogo, sendo que, no seu entender, as universidades têm um papel fundamental nesse processo.

Nos últimos dois capítulos, Horacio Capel oferece uma síntese sobre a evolução das suas preocupações enquanto académico e das linhas de investigação que desenvolveu ao longo da sua carreira, designadamente sobre redes e morfologia urbana, História, Epistemologia, Filosofia e metodologias da Ciência Geográfica e, ainda, sobre a História da Ciência em geral.

A estes nove capítulos junta-se ainda um epílogo, no qual o autor nos fala do presente e do futuro, destacando o papel que a educação tem na construção de um futuro melhor.

Ao relatar-nos a sua vida académica e pessoal Horacio Capel conduz-nos numa viagem por dentro do mundo académico da Geografia institucional espanhola, ajudando-nos a perceber as suas evoluções e orientações ao longo de um significativo período histórico, quer cientificamente, com o surgimento de novos paradigmas nas ciências geográficas, quer politicamente, com a transição democrática em Espanha.

A leitura da obra oferece-nos os pormenores da atividade de um geógrafo inovador que desde cedo assumiu um papel central na Geografia espanhola. Para além das muitas informações que concede e que são do interesse de todos aqueles que desejem compreender a evolução histórica da ciência geográfica em Espanha, o presente livro constitui também uma excelente oportunidade para seguir a evolução da ciência geográfica em geral e da importância que os sucessivos contextos históricos têm na evolução da própria Geografia. 
BENACH, Núria; CASALS, Vicente. Horacio Capel, una trayectoria científica entre la geografía urbana y la historia del pensamiento geográfico. Con-Ciencia Social, 2015, nº 20, p. 73-86.

CAPDEPÓN, Félix Pillet. Reseña de Azares y decisiones. Recuerdos personales. Investigaciones Geográficas, 2019, nº 71, p. 247-249.

CAPEL, Horacio. Azares y Decisiones: recuerdos personales. Madrid: Ediciones Doce Calles, 2019. 333 p. ISBN: 978-84-9744-250-3.

CARRERAS, Carles; VILAGRASA, Joan. Los estudios urbanos en Catalunya: un campo interdisciplinar. Cuadernos de historia - geografía, 1983, nº 1, p. 203-230.

GONZÁLEZ, Rubén. Una lectura critica de los escritos de Horacio Capel sobre la Geografía y las possibilidades de internet. Biblio 3W, Revista Bibliográfica de Geografía y Ciencias Sociales, 2013. Disponível em: <http://www.ub.edu/geocrit/b3w-1013-1.htm>. Acesso em: 15 set. 2020.

RAMÃO, Filipe. O Geógrafo Horacio Capel: estudos urbanos e a história do pensamento geográfico. Espaço e Economia: revista brasileira de geografia econômica, 2017, no 11. Disponível em: <https://journals.openedition.org/espacoeconomia/3093>. Acesso em: 15 set. 2020. 